\title{
EFEITO DA ESCÓRIA EM DIFERENTES DOSES E FRAÇÕES GRANULOMÉTRICAS NA PRODUTIVIDADE E ACÚMULO DE MATÉRIA SECA DE MILHO
}

\author{
Emerson Vinicius Silva do Nascimento ${ }^{1}$, Edilson Carvalho Brasil ${ }^{2}$, George Rodrigues da Silva ${ }^{1}$ \\ ${ }^{1}$ Universidade Federal Rural da Amazônia - UFRA, Belém - PA, E-mail: agrovinicius@yahoo.com.br, george.silva@edu.ufra.br \\ ${ }^{2}$ Embrapa Amazônia Oriental, Email: brasil@cpatu.embrapa.br
}

\section{RESUMO}

O objetivo do trabalho foi avaliar o efeito da ação da escória de siderurgia em diferentes doses e granulometrias na produção e no acúmulo de massa seca de plantas de milho. As granulometrias $100-200 \mathrm{e}<200$ associados a maior dose $5,91 \mathrm{t} \mathrm{ha}^{-1}$ proporcionaram melhores resultados nos caracteres agronômicos de plantas de milho.

Palavras-chave: Corretivo, matéria seca, produtividade, silicato, Zea mays

\section{EFFECT OF DIFFERENT DOSE SLAG AND GRAIN SIZE FRACTIONS IN THE PRODUCTIVITY AND ACCUMULATION OF CORN DRY MATTER}

\begin{abstract}
The objective of this study was to evaluate the effect of the action of the slag at different doses and particle sizes in the production and dry matter accumulation of corn plants. The grain sizes 100-200 and $<200$ associated with higher dose, $5.91 \mathrm{t} \mathrm{ha}^{-1}$, gave provided better results in agronomic characters of maize plants.
\end{abstract}

Keywords: Corrective, dry matter, productivity, silicate, Zea mays

\section{INTRODUÇÃO}

O milho (Zea mays L.) é considerado uma das principais espécies de cereais utilizadas no mundo. Foram cultivados no Brasil no ano de 2012 cerca de 15,3 milhões de hectares, os quais contribuíram para a produção de 80,5 milhões de toneladas
(IBGE, 2013). Ao milho deve-se ao aumento da produção de animais que dele se alimentam, como aves e suínos, sendo cerca de $70 \%$ de sua produção mundial destinada a esse fim (EMBRAPA, 2006). É fonte principalmente de carboidratos e lipídeos, sendo considerado um alimento energético, 


\section{EFEITO DA ESCÓRIA EM DIFERENTES DOSES E FRAÇÕES GRANULOMÉTRICAS NA PRODUTIVIDADE E ACÚMULO DE MATÉRIA SECA DE MILHO}

muito consumido na zona rural do Brasil, também utilizado em uma ampla variedade de pratos (NAVES et al., 2004). O milho assume importância ainda maior na contextualização da agricultura familiar, sendo um dos pilares do cultivo de subsistência e da alimentação das famílias, fortalecendo a economia solidária.

A área cultivada com milho no estado do Pará não pode ser considerada expressiva, se forem levadas em conta as condições de solo, topografia e clima para desenvolvimento da cultura. No estado do Pará a área cultivada com milho em 2011, foi de 210.634 ha e uma produção da ordem de 541.128 t e um rendimento médio de $2.570 \mathrm{~kg} \mathrm{ha}^{-1}$, números esses considerados baixos se comparados à média brasileira que foi de $4.210 \mathrm{~kg} \mathrm{ha}^{-1} \mathrm{e}$ as médias obtidas pelas principais regiões produtoras, sul, sudeste e centro-oeste do país que foram de $5.405 \mathrm{~kg}$ $\mathrm{ha}^{-1}, 4.995 \mathrm{~kg} \mathrm{ha}^{-1}$ e $4.485 \mathrm{~kg} \mathrm{ha}{ }^{-1}$ respectivamente (IBGE, 2011).

A baixa produtividade do milho no estado do Pará pode estar relacionada ao baixo nível tecnológico empregado na produção, tais como uso de cultivares não melhoradas, baixo uso de defensivos agrícolas e, principalmente, o uso de adubação inadequada e a cultura ser implantada em sua grande maioria em
Latossolos caracterizados pela elevada acidez e baixa saturação por bases (VELOSO et al., 2001).

No Brasil, as rochas carbonatadas moídas, genericamente denominadas calcárias, são os materiais predominantemente empregados na agricultura como corretivo da acidez do solo. Entretanto, existem materiais corretivos alternativos, sendo o mais promissor as escórias de siderurgias (PRADO et al., 2001), que apesar de estarem disponíveis no mercado brasileiro, têm sido pouco comercializadas para uso na agricultura (QUAGGIO, 2000). Segundo Korndörfer et al. (2004), a aplicação de escórias silicatadas de cálcio e magnésio $\left(\mathrm{CaSiO}_{3}\right.$ e $\left.\mathrm{MgSiO}_{3}\right)$ promove benefícios ao solo. Esses silicatos estão associados ao aumento na disponibilidade de $\mathrm{Si}$, elevação do $\mathrm{pH}$ e aumento do $\mathrm{Ca}$ e $\mathrm{Mg}$ trocável do solo, indiretamente propiciando incremento na disponibilidade de fósforo e podendo, ainda, atuar na redução da toxidade de $\mathrm{Fe}, \mathrm{Mn}$ e $\mathrm{Al}$ para as plantas (PRADO et al., 2002).

A maioria das pesquisas desenvolvidas no Brasil com escória avaliou, predominantemente, seu efeito corretivo e como fonte de alguns nutrientes presentes na sua composição. Assim, pesquisas realizadas nas culturas de cana-de-açúcar (PRADO \& 
FERNANDES, 2001) e maracujá (PRADO \& NATALE, 2004), procuraram verificar a resposta de sua aplicação dentro de cada cultura proporcionando aumentos significativos nos valores de $\mathrm{pH}, \mathrm{Ca}, \mathrm{Mg}$ e $\mathrm{Si}$ e redução na acidez potencial $(\mathrm{H}+\mathrm{Al})$ e consequentemente melhorias em seu desenvolvimento e suas produções.

Com isso objetivou-se com este trabalho avaliar o efeito de diferentes doses escória de siderúrgicas em diferentes granulometrias nas características agronômicas da cultura do milho.

\section{MATERIAL E MÉTODOS}

O trabalho foi conduzido no Campo Experimental da Embrapa Amazônia Oriental, localizado no município de Terra Alta no Estado do Pará, distante cerca de 100 km de Belém, no km 33 da Rodovia Castanhal/Curuçá, que faz parte da Microrregião do Salgado nas seguintes coordenadas geográficas, Latitude $01^{\circ} 01^{\prime} 7,72^{\prime \prime}$ Sul e Longitude 47º53'29,19" Oeste. Essa área está sob a influência climática do tipo Am, da classificação de Köppen, caracterizado por apresentar um índice pluviométrico elevado, com total anual de $2.000 \mathrm{~mm}$ aproximadamente e temperatura média de $26^{\circ} \mathrm{C}$.
O solo foi classificado como Latossolo Amarelo distrófico, textura média (EMBRAPA, 2006), Antes da instalação do experimento foram coletadas amostras na camada superficial $(0-20 \mathrm{~cm})$, para caracterização química e física do solo. As análises foram realizadas segundo metodologia da Embrapa (1997), apresentando as seguintes características químicas e físicas: $\mathrm{pH}$ em água $(1: 2,5)=4,9$; $\mathrm{Ca}\left(\mathrm{cmolc} \mathrm{dm}^{-3}\right)=0,6 ; \mathrm{Mg}\left(\right.$ cmolc $\left.\mathrm{dm}^{-3}\right)=$ 0,$3 ; \mathrm{K}\left(\mathrm{cmolc} \mathrm{dm}^{-3}\right)=0,06 ; \mathrm{H}+\mathrm{Al}(\mathrm{cmolc}$ $\left.\mathrm{dm}^{-3}\right)=4,38 ; \mathrm{P}(\mathrm{mg} \mathrm{dm}-3)=2,0 ;$ CTC a $\mathrm{pH}$ $7=5,34 ; \mathrm{V} \%=17,09$. Argila $\left(\mathrm{g} \mathrm{kg}^{-1}\right)=149 ;$ Areia $\left(\mathrm{g} \mathrm{kg}^{-1}\right)=736$ e Silte $\left(\mathrm{g} \mathrm{kg}^{-1}\right)=115$.

Utilizou- se um delineamento experimental em blocos casualizados, em esquema fatorial $4 \times 3$, sendo quatro frações granulométricas da escória (material retido entre as peneiras ABNT 20-50, 50-100, 100200 e <200), três doses da escória equivalentes a 1,65; 3,81 e 5,98 $\mathrm{t} \mathrm{ha} \mathrm{ha}^{-1}$, necessárias para elevar a saturação por bases inicial do solo para 40, 70 e 100\%, respectivamente, em três blocos, totalizando 36 parcelas com dimensões de $28 \mathrm{~m}^{2}(5,6 \mathrm{~m}$ x5,0m). Para definir as doses de escória, foi adotado o método de saturação por bases (RAIJ et al., 2001) a partir dos dados obtidos de análise química inicial do solo. A escória utilizada foi coletada em vazamentos de um 


\section{EFEITO DA ESCÓRIA EM DIFERENTES DOSES E FRAÇÕES GRANULOMÉTRICAS NA PRODUTIVIDADE E ACÚMULO DE MATÉRIA SECA DE MILHO}

alto forno da Usina Siderúrgica do Pará (USIPAR), localizada no município de Barcarena, Estado do Pará. O resíduo passou pelo processo de secagem e posterior moagem em um triturador. Depois de triturada a escória passou pelo processo de peneiramento utilizando as peneiras 0,850 mm (ABNT $\left.\mathrm{N}^{\mathrm{o}} 20\right), 0,300 \mathrm{~mm}\left(\mathrm{ABNT} \mathrm{N}^{\mathrm{o}}\right.$ 50), 0,150 mm (ABNT No 100) e $0,075 \mathrm{~mm}$ (ABNT $\mathrm{N}^{\mathrm{o}}$ 200), obtendo-se as quatro granulometrias usadas no experimento.

Foi retirada uma amostra do resíduo cuja análise em Laboratório apresentou as seguintes características químicas: $\mathrm{CaO}$ (dag $\left.\mathrm{kg}^{-1}\right)=24,85 ; \mathrm{MgO}\left(\operatorname{dag} \mathrm{kg}^{-1}\right)=12,49 ; \mathrm{PN}$ $(\%)=75 ; \operatorname{PRNT}(\%)=74 ; \operatorname{Si}\left(\mathrm{mg} \mathrm{kg}^{-1}\right)=$ 6,34; $\mathrm{Cd}\left(\mathrm{mg} \mathrm{kg}^{-1}\right)$ 10,5; $\mathrm{Cr}\left(\mathrm{mg} \mathrm{kg}^{-1}\right)=42,1$; $\mathrm{Ni}\left(\mathrm{mg} \mathrm{kg}^{-1}\right)=40,0$ e $\mathrm{Pb}\left(\mathrm{mg} \mathrm{kg}^{-1}\right)=24,1$. A metodologia empregada na realização das análises de corretivo agrícola, na qual se inclui a escória, segue o protocolo do MAPA (2007). A escória apresentou resultados dentro dos limites máximos de contaminantes admitidos em corretivos de acidez (MAPA, 2006).

Os corretivos foram aplicados manualmente a lanço em cada parcela no mês de dezembro de 2009, colocando-se metade das quantidades estimadas antes da aração e a outra metade, antes da gradagem. Todas as parcelas receberam o equivalente a
$90 \mathrm{~kg} \mathrm{ha}^{-1} \mathrm{de} \mathrm{P}_{2} \mathrm{O}_{5}$, na recomendação máxima sugerida no estado do Pará (CRAVO et al., 2010) na forma de superfosfato simples e 40 $\mathrm{kg} \mathrm{ha}^{-1}$ de FTE BR-12, aplicados a lanço em área total junto com os tratamentos.

A parcela experimental tinha 5,6 $\mathrm{m} \times$ 5,0 m, com oito linhas de milho, espaçadas em $0,8 \mathrm{~m}$, tendo cinco plantas por metro linear. As sementes de milho (Zea mays L. cV. BRS 1030, híbrido simples, ciclo precoce) foram semeadas em janeiro de 2010.Efetuou-se também adubação de $90 \mathrm{~kg}$ ha ${ }^{-1}$ de $\mathrm{N}$ e $60 \mathrm{~kg} \mathrm{ha}^{-1}$ de $\mathrm{K}_{2} \mathrm{O}$. A adubação foi parcelada em duas vezes aos 15 e 45 dias após a emergência do milho. No primeiro parcelamento, aplicaram-se $50 \mathrm{~kg} \mathrm{ha}^{-1} \mathrm{de} \mathrm{Ne}$ $30 \mathrm{~kg} \mathrm{ha}^{-1}$ de $\mathrm{K}_{2} \mathrm{O}$, na forma de sulfato de amônio e cloreto de potássio, respectivamente, em sulcos na linha de plantio, enquanto no segundo parcelamento foram aplicados $40 \mathrm{~kg} \mathrm{ha}^{-1}$ de $\mathrm{N}$ e $30 \mathrm{~kg} \mathrm{ha}^{-1}$ de $\mathrm{K}_{2} \mathrm{O}$ na forma de ureia e cloreto de potássio, respectivamente, em cobertura na linha de plantio. Utilizou-se o parcelamento do nitrogênio e potássio devido a elevada precipitação pluviométrica na região, reduzindo a perda desses nutrientes devido a fácil volatilização dos mesmos.

Após a floração efetuou-se a colheita de plantas de milho para a determinação da massa seca da parte aérea, coletando-se duas 
plantas de cada uma das quatros linhas centrais das parcelas totalizando oito plantas por parcela. As plantas foram coletadas de forma aleatória procurando-se amostras de plantas normais e representativas de cada parcela. O corte foi feito na base das plantas, após a coleta das plantas estas foram acondicionadas em sacos de papéis e colocadas para secar em estufa com circulação de ar forçado mantendo-se a temperatura na faixa de $65{ }^{\circ} \mathrm{C}-70{ }^{\circ} \mathrm{C}$. Após atingirem o peso constante as plantas foram pesadas em balança digital para obtenção da massa seca da parte aérea (MSPA) que foi estimada em t.ha ${ }^{-1}$.

A colheita foi realizada manualmente 120 dias após a semeadura. A produção de grãos foi avaliada após a maturação fisiológica em área útil de $11,4 \mathrm{~m}^{2}$ e a massa de grãos foi corrigida para $13 \%$ de umidade. As espigas foram despalhadas e debulhadas manualmente separando-se palha, grãos e sabugo. Depois de separadas as três partes foram pesadas em balança digital para obtenção do peso de palha (PP), peso de sabugo (PS) e peso de grão (PG). O peso de espiga (PE) foi a somatória dos pesos citados e foram estimadas em t.ha ${ }^{-1}$.

Os dados de produtividade foram submetidos a análise de variância
(ANOVA), sendo as médias comparadas pelo teste de Tukey $(p<0,05)$.

\section{RESULTADOS E DISCUSSÃO}

A análise de variância revelou efeito significativo da interação granulometria (Gran X Doses) na massa seca da parte aérea (MSPA), produtividade de grãos (PG), no número de fileiras de grãos por espiga (NFGE), peso de cem grãos (PCG), comprimento de espigas (CE). Para o rendimento de espigas por parcelas (RE) houve significância apenas para as doses (Tabela 1).

Com a maior dose da escória $(5,98 \mathrm{t}$ $\mathrm{ha}^{-1}$ ) foram obtidos os maiores valores para MSPA, em todas as granulometrias, que variaram entre $11,45 \mathrm{tha}^{-1}$ (ABNT 20-50) a $14,04 \mathrm{tha}^{-1}(\mathrm{ABNT}<200)$. As maiores doses da escória 3,81 e 5,98 tha ${ }^{-1}$, em interação com as frações granulométricas mais finas 100-200 e $<200$, proporcionaram os maiores pesos de matéria seca da parte aérea. Nas granulometrias 100-200 e $<200$, quando a dose da escória foi igual a 3,81 $\mathrm{t} \mathrm{ha}^{-1}$, os valores de MSPA corresponderam a 12,38 $\mathrm{t}$ $\mathrm{ha}^{-1}$ e $13,35 \mathrm{t} \mathrm{ha}^{-1}$, enquanto que com 5,98 t $\mathrm{ha}^{-1}$ de escória, os valores foram iguais a 13,31 $\mathrm{t} \mathrm{ha}^{-1}$ e 14, 04t ha ${ }^{-1}$, respectivamente (Tabela 2). Os valores encontrados de MSPA nas frações granulométricas mais 


\section{EFEITO DA ESCÓRIA EM DIFERENTES DOSES E FRAÇÕES GRANULOMÉTRICAS NA PRODUTIVIDADE E ACÚMULO DE MATÉRIA SECA DE MILHO}

finas, entre 10,90 a $14,04 \mathrm{t}$ ha $\mathrm{a}^{-1}$ estão dentro da faixa de valores alcançados por Santos et al., (2010), que variaram entre 10,7 a $16,0 \mathrm{t}$ $\mathrm{ha}^{-1}, \quad$ ao avaliarem características agronômicas de seis variedades de milho para produção de silagem.

Independente das dosagens, as maiores produções de grãos de milho foram obtidas na granulometria mais fina $100-200$ e $<200$ com valores que variaram de $6,21 \mathrm{t} \mathrm{ha}^{-1} \mathrm{a}$ $6,72 \mathrm{t} \mathrm{ha}^{-1}$ nas doses 3,81 e $5,98 \mathrm{t} \mathrm{ha}^{-1}$ respectivamente, não apresentando diferenças significativas entre si (Tabela 3). No geral a dose $5,98 \mathrm{t} \mathrm{ha}^{-1}$ apresentaram maiores produções de grãos nas frações 20 50; 50-100; 100-200 e $<200$ que as demais doses.

Tabela 1. Análise de variância da massa seca da parte aérea (MSPA), produtividade de grãos (PG), número de fileiras de grãos por espiga (NFGE), massa de cem grãos (MCG), comprimento de espigas (CE) e rendimento de espigas por parcelas (RE) no município de Terra Alta - PA, 2012.

\begin{tabular}{cccccccc}
\hline FV & GL & \multicolumn{7}{c}{ QM } \\
\cline { 3 - 7 } & & MSPA & PG & NFGE & MCG & CE & RE \\
\hline Gran & 3 & $13,93^{*}$ & $5,58^{*}$ & $10,67^{*}$ & $201,5^{\mathrm{NS}}$ & $27,1^{*}$ & $175,0^{*}$ \\
Doses & 2 & $15,43^{*}$ & $6,21^{*}$ & $0,69^{*}$ & $55,32^{\mathrm{NS}}$ & $1,3^{*}$ & 72,00 \\
Gran * Doses & 6 & $0,57^{*}$ & $0,37^{*}$ & $0,05^{*}$ & $3,31^{\mathrm{NS}}$ & $0,35^{*}$ & 13,59 \\
Blocos & 2 & 8,26 & 2,41 & 0,02 & 2,35 & 0,01 & 8,58 \\
Residuos & 22 & & & & & & \\
\hline CV\% & & 6,48 & 8,68 & 7,1 & 2,14 & 2,9 & 5,3 \\
Média & & 11,63 & 5,65 & 14,03 & 38,41 & 21,5 & 91,0 \\
\hline
\end{tabular}

* Significativo a $5 \%$ de probabilidade, ${ }^{\text {NS Não-siginificativo. }}$

Tabela 2. Massa seca da parte aérea $\left(\mathrm{t} \mathrm{ha}^{-1}\right)$ de plantas de milho em função de diferentes doses e frações granulométricas de escória de siderurgia no município de Terra Alta - PA, 2012.

\begin{tabular}{cccc}
\hline Frações granulométricas & \multicolumn{3}{c}{ Doses de escória t.ha $^{-1}$} \\
\cline { 2 - 4 }$\left(\mathrm{ABNT} \mathrm{n}^{\mathrm{o}}\right)$ & 1,65 & 3,81 & 5,98 \\
\hline $20-50$ & $9,11 \mathrm{cB}$ & $9,66 \mathrm{~dB}$ & $11,45 \mathrm{dA}$ \\
$50-100$ & $10,73 \mathrm{bB}$ & $10,77 \mathrm{cB}$ & $12,4 \mathrm{cA}$ \\
$100-200$ & $10,9 \mathrm{abC}$ & $12,38 \mathrm{bB}$ & $13,31 \mathrm{bA}$ \\
$<200$ & $11,66 \mathrm{aC}$ & $13,35 \mathrm{aB}$ & $14,04 \mathrm{aA}$
\end{tabular}

Médias seguidas por letras minúsculas na coluna e maiúscula distintas na mesma linha diferem entre si, a $5 \%$ de probabilidade, pelo teste de Tukey $(\mathrm{P}<0,05)$. 
Tabela 3. Produtividade de grãos de plantas de milho em função de diferentes doses e frações granulométricas de escória de siderurgia no município de Terra Alta - PA, 2012.

Frações

Doses de escória t.ha ${ }^{-1}$

granulométricas

\begin{tabular}{cccc}
$\left(\mathrm{ABNT}^{\circ}\right)$ & 1,65 & 3,81 & 5,98 \\
\hline $20-50$ & $3,77 \mathrm{cB}$ & $4,18 \mathrm{cB}$ & $5,88 \mathrm{bA}$ \\
$50-100$ & $4,82 \mathrm{bB}$ & $5,32 \mathrm{bB}$ & $6,35 \mathrm{aA}$ \\
$100-200$ & $5,53 \mathrm{aB}$ & $6,21 \mathrm{aA}$ & $6,70 \mathrm{aA}$ \\
$<200$ & $5,80 \mathrm{aB}$ & $6,57 \mathrm{aA}$ & $6,72 \mathrm{aA}$
\end{tabular}

Médias seguidas por letras minúsculas na coluna e maiúsculadistintas na mesma linha diferem entre si, a $5 \%$ de probabilidade, pelo teste de Tukey $(\mathrm{P}<0,05)$.

Os valores de produção de grãos encontrados em função da interação doses e granulometrias100-200 e <200 da escória variaram entre 5,53 a $6,72 \mathrm{t} \mathrm{ha}^{-1}$ e estão dentro da média de produção de milho do município de Paragominas - PA, de 5,34 t $\mathrm{ha}^{-1}$ principal polo graneleiro do Estado do Pará no qual utilizam o calcário como principal fonte de corretivo de acidez, obtida no ano de 2010 (SAGRI, 2010), e dos valores conseguidos por Câmara (2007) que, estudando rendimento de grãos verdes e secos de cultivares de milho, obteve valores da ordem de 4,2 a 6,31 $\mathrm{t} \mathrm{ha}^{-1}$. Os referidos valores encontram-se acima da média do estado do Pará que foi de $2,57 \mathrm{t} \mathrm{ha}^{-1}$ no ano de 2011 (IBGE, 2011) e muito superiores aos alcançados no município de Terra Alta PA, que foram de $0,6 \mathrm{t} \mathrm{ha}^{-1}$, obtida no ano de 2010 (SAGRI, 2010).

Para o número de fileiras de grãos por espiga (NFGE), observou-se que os melhores resultados foram obtidos na interação das granulometrias mais finas da escoria, 100-200 e <200 com as maiores doses 3,81 e 5,98 t.ha ${ }^{-1}$, o qual variaram de 14,73 a 14,83 . Observou-se (Tabela 5) que em todas as dosagens os maiores comprimentos de espigas foram obtidos quando foi aplicada a escória nas granulometrias $<200$, variando de $22,8 \mathrm{~cm}$ na dosagem de 1,65 t.ha ${ }^{-1}, 23,16 \mathrm{~cm}$ na dosagem de 3,81 t.ha ${ }^{-1}$ e 23,4 cm na dosagem de 5,98 t.ha ${ }^{-1}$. Esses resultados foram superiores aos obtidos por Stacciarini et al., (2010) que, avaliando caracteres agronômicos na cultura do milho em diferentes densidades, obtiveram valores variando de 16,57 a 18,22 cm. Observou-se (Figura 1) que houve diferença significativa entre as frações granulométricas sendo que os rendimentos de espigas foram maiores nas frações mais finas 50-100, 100-200 e <200, não havendo diferenças entre elas. 


\section{EFEITO DA ESCÓRIA EM DIFERENTES DOSES E FRAÇÕES GRANULOMÉTRICAS NA \\ PRODUTIVIDADE E ACÚMULO DE MATÉRIA SECA DE MILHO}

Tabela 4. Médias de número de fileiras de grãos por espiga (NFGE), em função de diferentes doses e frações granulométricas de escória de siderurgia no município de Terra Alta PA, 2012.

\begin{tabular}{cccc}
\hline Frações granulométricas & \multicolumn{3}{c}{ Doses de escória t.ha $^{-1}$} \\
\cline { 2 - 4 }$\left(\mathrm{ABNT}^{\mathrm{o}}\right)$ & 1,65 & 3,81 & 5,98 \\
\hline $20-50$ & $12,13 \mathrm{~dB}$ & $12,33 \mathrm{cB}$ & $12,80 \mathrm{cA}$ \\
$50-100$ & $14,03 \mathrm{cB}$ & $14,50 \mathrm{abA}$ & $14,43 \mathrm{abA}$ \\
$100-200$ & $14,33 \mathrm{bB}$ & $14,73 \mathrm{aA}$ & $14,86 \mathrm{aA}$ \\
$<200$ & $14,56 \mathrm{aB}$ & $14,83 \mathrm{aA}$ & $14,83 \mathrm{aA}$
\end{tabular}

Médias seguidas por letras minúsculas na coluna e maiúscula distintas na mesma linha diferem entre si, a $5 \%$ de probabilidade, pelo teste de Tukey $(\mathrm{P}<0,05)$.

Tabela 5. Comprimento de espigas em função de diferentes doses e frações granulométricas de escória de siderurgia no município de Terra Alta - PA, 2012.

\begin{tabular}{cccc}
\hline \multirow{2}{*}{$\begin{array}{c}\text { Frações granulométricas } \\
\left(\mathrm{ABNT}^{\circ}\right)\end{array}$} & 1,65 & 3,81 & \multicolumn{3}{c}{ Doses de escória t.ha ${ }^{-1}$} \\
\cline { 2 - 4 } & $18,3 \mathrm{cA}$ & $18,2 \mathrm{dA}$ & $18,4 \mathrm{dA}$ \\
$50-50$ & $21,2 \mathrm{bB}$ & $21,5 \mathrm{cAB}$ & $21,7 \mathrm{cA}$ \\
$100-200$ & $22,6 \mathrm{aB}$ & $22,7 \mathrm{bAB}$ & $23,0 \mathrm{bA}$ \\
$<200$ & $22,8 \mathrm{aC}$ & $23,16 \mathrm{aB}$ & $23,4 \mathrm{aA}$ \\
\hline
\end{tabular}

Médias seguidas por letras minúsculas na coluna e maiúscula distintas na mesma linha diferem entre si, a $5 \%$ de probabilidade, pelo teste de Tukey $(\mathrm{P}<0,05)$.

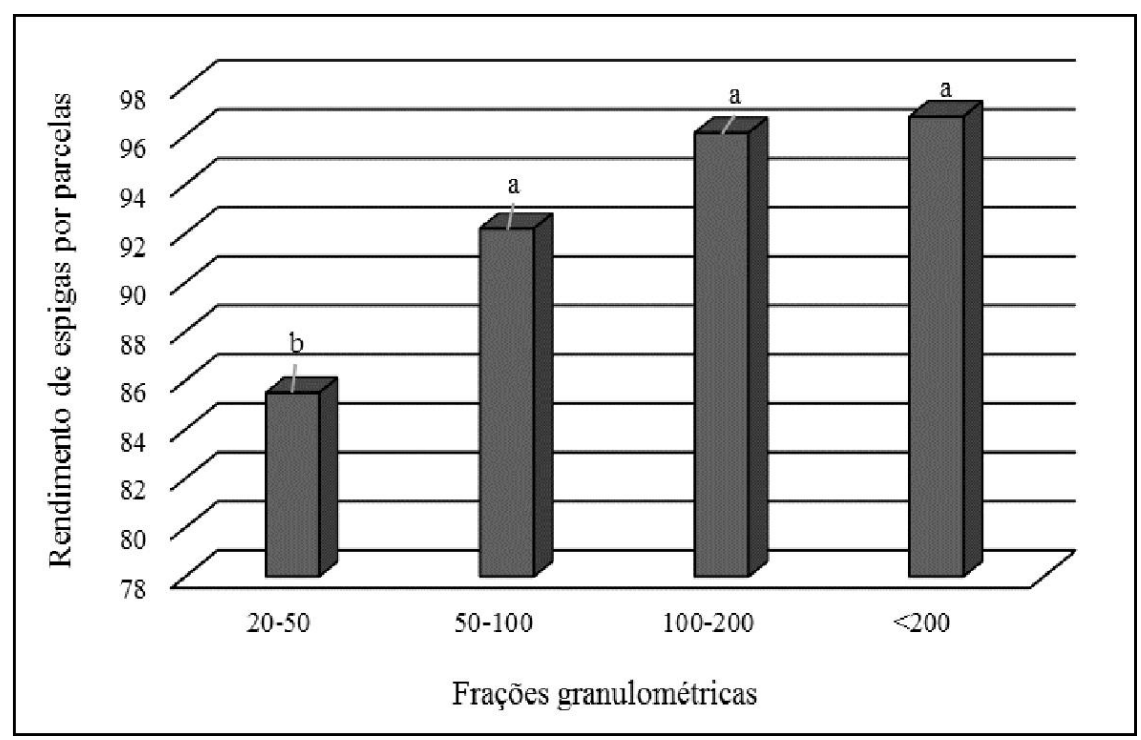

Figura 1. Rendimento de espigas por parcelas em função de diferentes frações granulométricas de escória no município de Terra Alta - PA, 2012. 


\section{CONCLUSÕES}

A aplicação da escória de siderurgia nas granulometrias $100-200$ e $<200$ associadas à maior dose $5,91 \mathrm{t} \mathrm{ha}^{-1}$ proporcionaram melhores resultados nos caracteres agronômicos de plantas de milho.

\section{REFERÊNCIAS BIBLIOGRÁFICAS}

BRASIL. 1983. Ministério da Agricultura. Secretaria Nacional de Defesa Agropecuária. Análise de corretivos, fertilizantes e inoculantes: métodos oficiais. Brasília: LANARV. 104 p.

CÂMARA T. M. M., 2007. Rendimento de grãos verdes e secos de cultivares de milho. Revista Ceres. Viçosa, v.54, n.311, p.87-92.

CRAVO, M. S.; SILVEIRA FILHO, A.; RODRIGUES, J. E. L.; VELOSO, C. A. C. 2010 Milho. In: CRAVO, M. S.; VIÉGAS, I. J. M.; BRASIL, E. C. (Ed.). Recomendações de adubação $e$ calagem para o Estado do Pará. 2. ed. rev. atual. Belém, PA: Embrapa Amazônia Oriental. p. 153-155p.

EMBRAPA. 1997. Centro Nacional de Pesquisa de Solos. Manual de métodos de análise de solo. Rio de Janeiro, 212 p. (EMBRAPA-CNPS. Documentos: 1).

EMPRESA BRASILEIRA DE PESQUISA AGROPECUÁRIA. 2006. Aspectos físicos, químicos e tecnológicos do grão de milho. EMBRAPA Milho e Sorgo. Sete Lagoas, Circular Técnica $75,6 \mathrm{p}$.

EMPRESA BRASILEIRA DE PESQUISA AGROPECUÁRIA - EMBRAPA. 2006. Centro Nacional de Pesquisa de Solos. Sistema brasileiro de classificação de solos. 2.ed. Brasília, Produção de Informação, 306p.
IBGE, Produção Agrícola Municipal. 2011 disponível em: ftp://ftp.ibge.gov.br/Pro ducão_Agricola/Producao_Agricola_Muni cipal_[anual]/2011/tabelas_pdf/tabela01.p df. Acesso em 4 de jan. 2013.

IBGE, Produção Agrícola Municipal 2011, disponível em: ftp://ftp.ibge.gov.br/Pro ducao_Agricola/Producao_A gricola_Mu nicipal_[anual]/2011/tabelas_pdf/tabela0 02.pdf. Acesso em 4 de jan. 2013.

IBGE, Levantamento Sistemático da Produção Agrícola 2013, disponível em: http://www.ibge.gov.br/home/estati stica/indicadores/agropecuária/lspa/lspa 201403 7.shtm, acesso em 12 de abril de 2014.

KORNDÖRFER, G. H; ARANTES, V. A.; CORRÊA, G. F.; SNYDER, G. H. 1999. Efeito do silicato de cálcio no teor de silício e na produção de grãos de arroz de sequeiro. Revista Brasileira de Ciência do Solo. Viçosa, v. 23, n. 3, p. 635-641.

KORNDÖRFER, G. H.; PEREIRA, H.S.; CAMARGO, M. S. 2004. Silicatos de cálcio e magnésio na agricultura. Uberlândia， GPSi/ICIAG/UFU， 28p. (Boletim Técnico, 1).

NAVES, M. M. V.; SILVA, M. S.; CERQUEIRA, F. M.; PAES, M. C. D.2004. Avaliação química e biológica da proteína do grão em cultivares de milho de alta qualidade proteica. Pesquisa Agropecuária Tropical. Goiânia, v.34, n.1, p.1-8.

PRADO, R. M.; COUTINHO, E. L. M.; ROQUE, C. G., PEREZ VILLAR, M. L.2002. Avaliação da escória de siderurgia e de calcários como corretivos da acidez do solo no cultivo da alface. Pesquisa Agropecuária Brasileira. Brasília, v. 37, n. 4, p. 539546.

PRADO, R. M.; FERNANDES, F. M.2001. Efeito da escória de siderurgia e calcário 
na disponibilidade de fósforo de um Latossolo Vermelho-Amarelo cultivado com cana-de açúcar. Pesquisa Agropecuária Brasileira. Brasília, v. 36, n. 9, p. 1199-1204.

PRADO, R. M.; NATALE, W. 2004. Efeitos da aplicação da escória de siderurgia ferrocromo no solo, no estado nutricional e na produção de matéria seca de mudas de maracujazeiro. Revista Brasileira de Fruticultura. Jaboticabal, v. 26, n. 1, p. 140-144.

QUAGGIO, J. A. 2000. A acidez e calagem em solos tropicais. Instituto Agronômico de Campinas: $111 \mathrm{p}$.

RAIJ, B. VAN.; ANDRADE, J. C.; CANTARELLA, H. ; QUAGGIO J. A. 2001. Eds. Análise química para avaliação da fertilidade do solo. Campinas, Instituto Agronômico de Campinas. 285p.

SAGRI, Dados estatísticos da produção agrícola do estado do Pará. 2010. Disponível em: http://www.sagri.pa.gov. br/pagina/agricultura. Acesso em 4 de jan. 2013.

SANTOS, R. F.; PEREIRA, L. G. R.; NEVES, A. L. A.; AZEVÊDO, J. A. G.; MORAES, S. A.; COSTA, C. T. F. 2010. Características agronômicas de variedades de milho para produção de silagem. Acta Scientiarum. Animal Sciences. Maringá, v. 32, n. 4, p. 367373.

SANTOS, J. F.; GRANGEIRO, J. I. T.; OLIVEIRA, M. E. C. 2012. Avaliação de cultivares e híbridos de milho para a microrregião de Campina Grande, PB. Tecnologia \& Ciência Agropecuária. João Pessoa, v.6, n.2, p.29-33.

STACCIARINI, T. C. V.; CASTRO, P. H. C. de; BORGES, M. A.; GUERIN, H. F.; MORAIS, P. A. C.; GOTARDO, M. 2010. Avaliação de caracteres agronômicos da cultura do milho mediante a redução do espaçamento entre linhas e aumento da densidade populacional. Revista Ceres. Viçosa. v. 57, n.4, p. 516-519.

VELOSO C. A. C.; SOUZA F. R. S. de; PEREIRA W. L. M.; TENÓRIO A. R. M. 2001. Relações cálcio, magnésio e potássio sobre a produção de matéria seca de milho. Acta Amazônica. Manaus v. 31(2), p 193-204.

Recebido em: $18 \backslash 10 \backslash 2013$ Aceito para publicação em:19\05\2015 